\title{
Maximum Sizes of Fluid-Occupied Pores within Hydrate-Bearing Porous Media Composed of Different Host Particles
}

\author{
Lele Liu $\left(\mathbb{D},{ }^{1,2}\right.$ Nengyou Wu $\left(\mathbb{D},{ }^{1,2}\right.$ Changling Liu $\mathbb{D},,^{1,2}$ Qingguo Meng, ${ }^{1,2}$ Haitao Tian, ${ }^{3}$ \\ Yizhao Wan, ${ }^{1,2}$ and Jianye Sun ${ }^{1,2}$ \\ ${ }^{1}$ Key Laboratory of Gas Hydrate, Ministry of Natural Resources, Qingdao Institute of Marine Geology, Qingdao 266071, China \\ ${ }^{2}$ Laboratory for Marine Mineral Resources, Qingdao National Laboratory for Marine Science and Technology, \\ Qingdao 266071, China \\ ${ }^{3}$ Institute of Geophysics and Geomatics, China University of Geosciences, Wuhan 430074, China
}

Correspondence should be addressed to Nengyou Wu; wuny@ms.giec.ac.cn and Changling Liu; qdliuchangling@163.com

Received 16 March 2020; Revised 26 May 2020; Accepted 4 June 2020; Published 15 July 2020

Academic Editor: Wei Wei

Copyright ( 92020 Lele Liu et al. This is an open access article distributed under the Creative Commons Attribution License, which permits unrestricted use, distribution, and reproduction in any medium, provided the original work is properly cited.

Hydraulic properties of hydrate-bearing sediments are largely affected by the maximum size of pores occupied by fluids. However, effects of host particle properties on the maximum size of fluid-occupied pores within hydrate-bearing sediments remain elusive, and differences in the maximum equivalent, incircle, and hydraulic diameters of fluid-occupied pores evolving with hydrate saturation have not been well understood. In this study, numerical simulations of grain-coating and pore-filling hydrate nucleation and growth within different artificial porous media are performed to quantify the maximum equivalent, incircle, and hydraulic diameters of fluid-occupied pores during hydrate formation, and how maximum diameters of fluid-occupied pores change with hydrate saturation is analyzed. Then, theoretical models of geometry factors for incircle and hydraulic diameters are proposed based on fractal theory, and variations of fluid-occupied pore shapes during hydrate formation are discussed. Results show that host particle properties have obvious effects on the intrinsic maximum diameters of fluid-occupied pores and introduce discrepancies in evolutions of the maximum pore diameters during hydrate formation. Pore-filling hydrates reduce the maximum incircle and hydraulic diameters of fluid-occupied pores much more significantly than grain-coating hydrates; however, hydrate pore habits have minor effects on the maximum equivalent diameter reduction. Shapes of fluid-occupied pores change little due to the presence of grain-coating hydrates, but pore-filling hydrates lead to much fibrous shapes of fluidoccupied pores.

\section{Introduction}

Natural gas hydrates vastly stored in marine sediments along the continental margins have a great potential to become one of global unconventional hydrocarbon energy resources [1-3]. Currently, the exploitation of this potential energy resource is still not economically feasible and requires innovative production methods and techniques $[4,5]$. New methods and techniques should be well evaluated by numerical simulators prior to field applications, and results of these numerical evaluations largely depend on proper characterizations of coupled processes and appropriate quantifications of physical properties of hydrate-bearing sediments [6-9].
Hydraulic properties of hydrate-bearing sediments are quite crucial [10-12], and they still represent an ongoing research issue although great effort has been made [13-16].

Hydraulic properties (e.g., saturated water permeability, water retention curve, and relative permeability to water and gas) of hydrate-bearing sediments are inherently governed by pore-scale structures of the solid matrix and pores $[17-20]$. The pore space occupied by water and/or gas within hydrate-bearing sediments shrinks due to solid hydrate formation, and structures of fluid-occupied pores can be highly diverse due to different hydrate pore habits (e.g., graincoating and pore-filling) even though hydrate saturations are identical. These diverse pore structures are experimentally 
observed, and how they change during hydrate formation or dissociation has been quantified by using varieties of parameters with clear physical significances. Examples include porosity, shape factor, Euler characteristic of individual hydrate cluster, fractal dimensions, pore surface, and pore volume and size [21-24]. Various pore sizes (e.g., the critical, mean, and maximum pore sizes) have been correlated to the hydraulic permeability of porous media, and larger pore sizes generally lead to higher values of the hydraulic permeability [25-27]. Hydraulic properties of porous media are significantly affected by the maximum pore size [27-29], and the maximum pore size is experimentally and theoretically correlated with porosity, permeability, and particle size [30-33]. Grain sizes of marine sediments hosting natural gas hydrates are of a wide range from clays and silts to coarsegrained sands, and sand particle shapes are generally different [34-36]. Effects of host sediments properties (e.g., porosity, grain size, and shape) on the maximum size of fluidoccupied pores within hydrate-bearing sediments remain elusive, although papers have been published to clarify how the maximum size of fluid-occupied pores evolve with hydrate saturation during hydrate formation and dissociation $[23,37]$.

Pores and fluid channels within most porous media in nature are generally nonspherical and noncircular [38-40]. For these irregularly shaped pores, several definitions of pore diameter are applied to quantify pore sizes. Examples include the equivalent diameter [41], the incircle diameter, and the hydraulic diameter [42]. The equivalent diameter $\lambda_{\mathrm{e}}$ is a diameter of a circle having an area equal to the pore area. The incircle diameter $\lambda_{\mathrm{i}}$ is determined by using the maximum ball method [43], and it is widely applied to pore network extractions from porous media $[16,24,44]$. The hydraulic diameter $\lambda_{\mathrm{h}}$ is defined as $\lambda_{\mathrm{h}}=4 A / P$, where $A$ is the cross-sectional area and $P$ is the wetted perimeter of the cross-section. The hydraulic diameter is commonly used to simplify fluid flow in noncircular tubes and channels as round pipe flow $[17,45,46]$. For fluid-occupied pores within hydrate-bearing sediments, the maximum pore size is expected to decrease with increasing hydrate saturation. However, similarities and differences in the maximum equivalent, incircle, and hydraulic diameters of fluid-occupied pores evolving with hydrate saturation have not been well understood.

This study is aimed at clarifying the effects of host particle properties on the maximum size of fluid-occupied pores within hydrate-bearing porous media and further the understanding of different maximum pore diameters evolving with hydrate saturation. Grain-coating and pore-filling hydrates are randomly nucleated and grew within different artificial porous media to quantify the maximum equivalent, incircle, and hydraulic diameters of fluid-occupied pores at selected hydrate saturations, followed by analyses of maximum fluid-occupied pore diameters changing due to the presence of gas hydrates. Then, theoretical models for incircle and hydraulic diameter-related geometry factors are proposed based on the fractal theory, and these proposed models are further applied to provide insights into the hydrate saturation and morphology-dependent pore shape changes during hydrate formation.

\section{Methods}

Ten square images of artificial porous media shown in Figure 1(a) are generated by using the method of [47] for further numerical simulations of hydrate nucleation and growth in this study. Each of these porous media is constructed by randomly placing black particles with unrestricted overlap into a white square image until the desired porosity has been reached. The porosity is calculated as the ratio of white over total pixel numbers in a square image, and the square image has a side length of 300 pixels. The shape of a solid particle is characterized by using a concept of sphericity which is defined as $S=2 \sqrt{\pi A_{s}} / P_{s}$, where $A_{\mathrm{s}}$ is the area and $P_{\mathrm{s}}$ is the perimeter of the solid particle [48]. Particle sphericity values are normally no bigger than 1 , and $S=1$ represents a circular solid particle. In addition, $S=0.86$ stands for an elliptical solid particle with a major over minor diameter ratio of 2 , and $S=0.76$ for a diameter ratio of 3 . Sphericity and size values of solid particles used for porous media constructions are summarized in Figure 1(b), and Figure 1(c) shows the intrinsic porosity and median particle diameter map for those artificial porous media.

Random nucleation and growth of grain-coating and pore-filling hydrates within artificial porous media is numerically simulated by using the method of [37]. These numerical simulations continually calculate minimum distances $d_{\text {s }}$ of fluid-occupied pore pixels to solid particle and hydrate pixels, and fluid-occupied pore pixels are selectively turned into hydrate pixels until the desired hydrate saturation $S_{\mathrm{h}}$ has been reached. Different nucleation and growth preferences represent different hydrate pore habits. Grain-coating hydrate nucleation and growth is simulated by stochastically changing candidate pore pixels with $d_{\mathrm{s}}=1 \mathrm{px}$ into hydrate pixels. Pore-filling hydrate nucleation and growth is modeled by preferentially seeding hydrate in candidate pore pixels with the highest $d_{s}$, followed by randomly changing hydrate-touched pore pixels into hydrate pixels, and the value of the growth parameter is set to be 0.7 in this study. Each case of numerical simulations is 100 times performed to obtain probabilistically acceptable results. For more details, please refer to our previous paper [37].

The maximum equivalent $\Lambda_{\mathrm{e}}$, incircle $\Lambda_{\mathrm{i}}$, and hydraulic $\Lambda_{\mathrm{h}}$ diameters of fluid-occupied pores within hydratebearing porous media are quantified from $S_{\mathrm{h}}=0$ to $S_{\mathrm{h}}=0.8$ at intervals of $S_{\mathrm{h}}=0.1$. When a preselected hydrate saturation is reached, fluid-occupied pores are extracted from hydrate-bearing porous media by using the function named "bwlabel" with $n=4$ (i.e., 4 connected pixels) in MATLAB 2016Ra, followed by calculations of the area and perimeter for all the fluid-occupied pores. Calculated values of the area and perimeter are further used to determine values of equivalent $\lambda_{\mathrm{e}}$ and hydraulic $\lambda_{\mathrm{h}}$ diameters, and the incircle diameter $\lambda_{\mathrm{i}}$ is quantified by using minimum distance $d_{\mathrm{s}}$ values. Assuming that there is a rectangular fluid-occupied pore with side lengths of $5 \mathrm{px}$ and $6 \mathrm{px}$ in hydrate-bearing porous media (Figure 2(a)), the equivalent diameter is calculated to be $\lambda_{\mathrm{e}}=6.2 \mathrm{px}$, the incircle diameter $\lambda_{\mathrm{i}}=5.0 \mathrm{px}$, and the hydraulic diameter $\lambda_{\mathrm{h}}=5.5 \mathrm{px}$ according to their definitions (Figure 2(b)). Values of the maximum equivalent, incircle, 

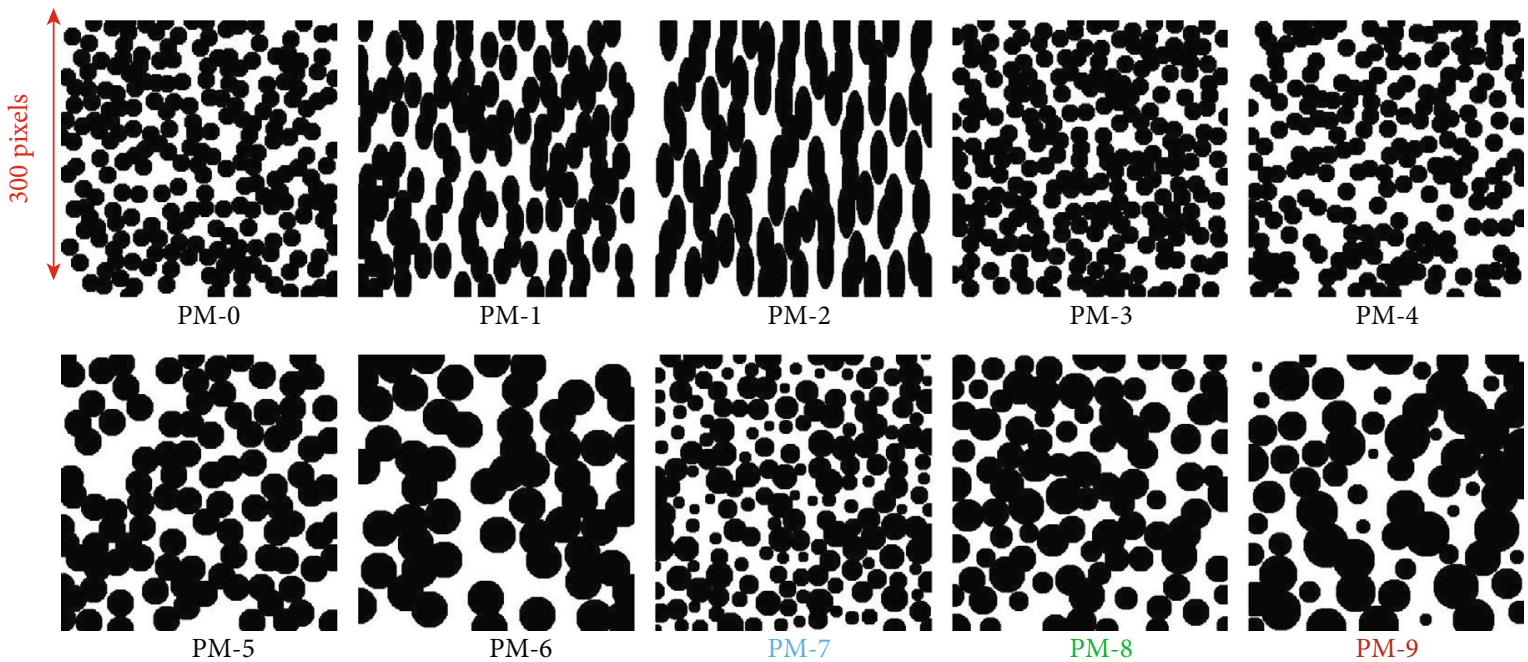

(a)

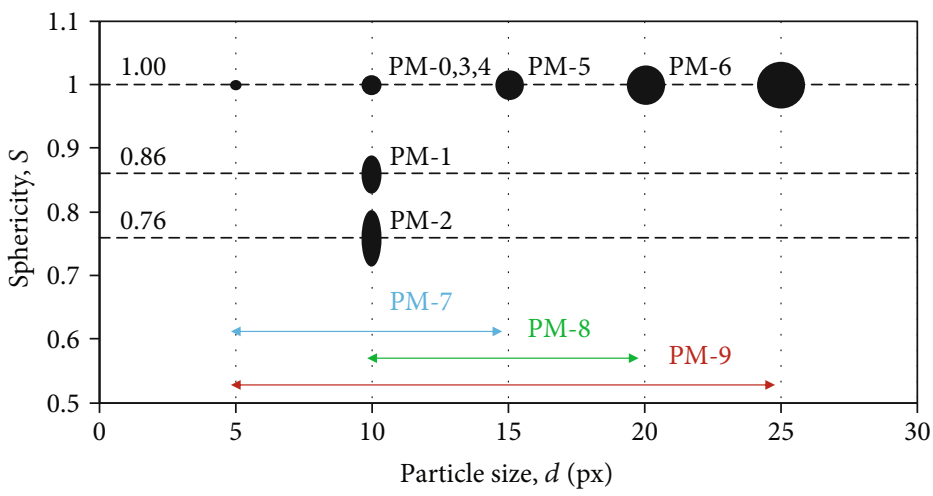

(b)

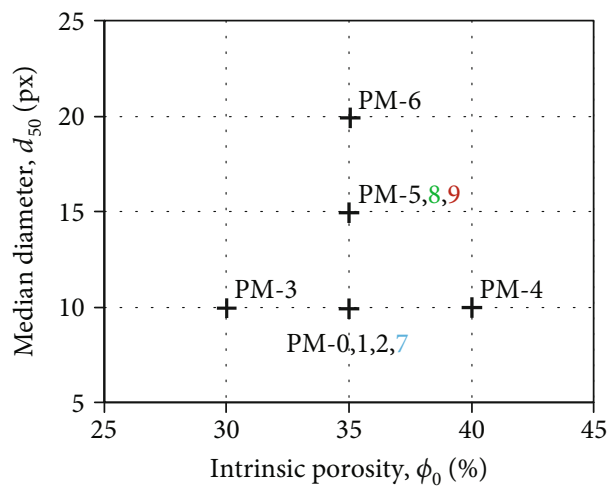

(c)

Figure 1: Artificial porous media for further numerical simulations of hydrate nucleation and growth in this study. (a) Square images of artificial porous media constructed by randomly placing and freely overlapping particles. The side length of square images is 300 px. Black color represents solid particles, and white color stands for fluid-occupied pores. (b) Size $d$ and sphericity $S$ of solid particles used for porous media constructions. (c) Intrinsic porosity $\phi_{0}$ of artificial porous media and median diameter $d_{50}$ of solid particles.

and hydraulic diameters of pores within hydrate-free porous media are determined and summarized in Figure 2(c) as intrinsic maximum pore diameters.

\section{Results}

The maximum equivalent $\Lambda_{\mathrm{e}}$, incircle $\Lambda_{\mathrm{i}}$, and hydraulic $\Lambda_{\mathrm{h}}$ diameters of fluid-occupied pores within ten images of porous media containing gas hydrates are shown in Figure 3, and all the pore diameters decrease with increasing hydrate saturation $S_{\mathrm{h}}$. The average value of intrinsic maximum equivalent diameters $\Lambda_{\mathrm{e} 0}$ of fluid-occupied pores within ten porous media (Figure $1(\mathrm{a})$ ) is $154.7 \pm 41.1 \mathrm{px}$ with a confidence interval of $95.4 \%$ (the same below), and it decreases to $29.7 \pm 16.7 \mathrm{px}$ (19.2\% of the intrinsic value) and $5.6 \pm 1.3 \mathrm{px}$ (3.6\% of the intrinsic value) when hydrate saturation $S_{\mathrm{h}}$ is 0.8 for grain-coating (Figure 3(a)) and pore-filling (Figure 3(b)) hydrates, respectively. The average value of intrinsic maximum incircle diameters $\Lambda_{\mathrm{i} 0}$ of fluidoccupied pores within ten porous media is $47.8 \pm 23.3 \mathrm{px}$, and it decreases to $28.0 \pm 16.7 \mathrm{px}$ (58.6\% of the intrinsic value) for grain-coating hydrates (Figure 3(c)) and $1.0 \pm 0.0$ px $(2.1 \%$ of the intrinsic value) for pore-filling hydrates (Figure 3(d)) when $S_{\mathrm{h}}=0.8$. The average value of intrinsic maximum hydraulic diameters $\Lambda_{\mathrm{h} 0}$ of fluid-occupied pores within ten porous media is $19.7 \pm 9.1 \mathrm{px}$, and it decreases to $10.7 \pm 3.7 \mathrm{px}$ ( $54.3 \%$ of the intrinsic value) and $4.7 \pm 0.6 \mathrm{px}$ (23.9\% of the intrinsic value) when $S_{\mathrm{h}}=0.8$ for graincoating (Figure 3(e)) and pore-filling (Figure 3(f)) hydrates, respectively. It is obvious that pore-filling hydrates reduce values of the maximum equivalent, incircle, and hydraulic diameters more efficiently than grain-coating hydrates when $S_{\mathrm{h}}=0.8$, and the maximum hydraulic diameter is the least sensitive to hydrate saturation.

Host particle properties (e.g., intrinsic porosity, particle size, and sphericity) obviously affect the intrinsic maximum equivalent $\Lambda_{\mathrm{e} 0}$, incircle $\Lambda_{\mathrm{i} 0}$, and hydraulic $\Lambda_{\mathrm{h} 0}$ diameters of fluid-occupied pores (Figure 2(c)) and introduce diversities (41.1 px for $\Lambda_{\mathrm{e} 0}, 23.3 \mathrm{px}$ for $\Lambda_{\mathrm{i} 0}$, and $9.1 \mathrm{px}$ for $\Lambda_{\mathrm{h} 0}$ ) in values of the intrinsic maximum pore diameter. All the intrinsic diversities decrease due to the presence of gas hydrates, and this implies that effects of host particle properties decrease 


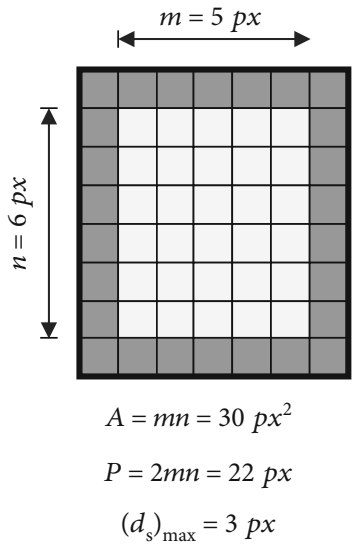

(a)

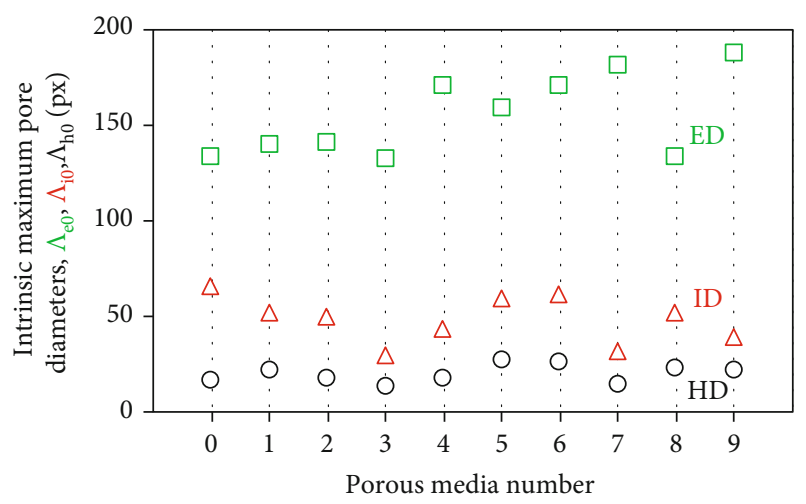

(c)

FIGURE 2: Equivalent, incircle, and hydraulic diameters of fluidoccupied pores within hydrate-bearing and hydrate-free porous media. (a) A pixel map of a rectangular pore occupied by fluids within hydrate-bearing porous media. Light gray pixels stand for the fluid-occupied pore with side lengths of 5 and $6 \mathrm{px}$, while dark gray pixels represent solid particle and hydrate pixels. Area $A$ of the pore is $30 \mathrm{px}^{2}$, and perimeter $P$ is $22 \mathrm{px}$. Symbol $d_{\mathrm{s}}$ represents the minimum distances of pore pixels to solid particle and hydrate pixels, and the maximum value $\left(d_{s}\right)_{\max }$ in the rectangular pore is 3 px. (b) Values of equivalent $\lambda_{\mathrm{e}}$, incircle $\lambda_{\mathrm{i}}$, and hydraulic $\lambda_{\mathrm{h}}$ diameters for the rectangular pore shown in (a). (c) Values of intrinsic maximum equivalent $\Lambda_{\mathrm{e} 0}$, incircle $\Lambda_{\mathrm{i} 0}$, and hydraulic $\Lambda_{\mathrm{h} 0}$ diameters in hydrate-free artificial porous media shown in Figure 1(a).

with increasing hydrate saturation. In addition, pore-filling hydrates (Figures 3(b), 3(d), and 3(f)) have more significant effects on the intrinsic diversity reductions than grainfilling hydrates (Figures 3(a), 3(c), and $3(\mathrm{e})$ ) when $S_{\mathrm{h}}=0.8$.

In order to obtain further understandings of hydrate saturation and morphology-dependent maximum equivalent, incircle, and hydraulic diameters, Figure 4 shows normalized maximum equivalent $\Lambda_{\mathrm{e}}{ }^{*}$, incircle $\Lambda_{\mathrm{i}}{ }^{*}$, and hydraulic $\Lambda_{\mathrm{h}}{ }^{*}$ diameters of fluid-occupied pores within hydrate-bearing porous media. Normalized maximum pore diameters are defined as ratios of maximum pore diameters within hydrate-bearing over hydrate-free porous media. All the values of normalized maximum equivalent diameters $\Lambda_{\mathrm{e}}{ }^{*}$ of fluid-occupied pores within porous media containing grain-coating (Figure 4(a)) and pore-filling (Figure 4(b)) hydrates generally fall into the region between upper $\Lambda_{\mathrm{e}}{ }^{*}=$ $\sqrt{1-S_{\mathrm{h}}}$ and lower $\Lambda_{\mathrm{e}}{ }^{*}=1-\sqrt{S_{\mathrm{h}}}$ curves, with $\Lambda_{\mathrm{e}}{ }^{*}$ values partially lower than $1-\sqrt{S_{\mathrm{h}}}$ when hydrate saturation is lower (i.e., $S_{\mathrm{h}}<0.5$ ) for grain-coating hydrates and higher (i.e., $S_{\mathrm{h}}$ $>0.5)$ for pore-filling hydrates. These two models are derived based on the assumption that gas hydrates uniformly grow into all pores with different sizes, and for their derivations, refer to $[29,37]$. Pore-filling hydrates reduce normalized maximum incircle (Figure 4(d)) and hydraulic (Figure 4(f)) diameters of fluid-occupied pores more significantly than grain-coating hydrates (Figures 4(c) and 4(e)). Normalized maximum incircle and hydraulic diameters of fluid-occupied pores decreasing due to the presence of grain-coating hydrates (Figures 4(c) and 4(e)) can be generally described by using $\Lambda_{\mathrm{i}, \mathrm{e}}{ }^{*}=\sqrt{1-S_{\mathrm{h}}}$. Normalized maximum incircle diameter $\Lambda_{\mathrm{i}}{ }^{*}$ of fluid-occupied pores within porous media containing pore-filling hydrates decreases with increasing hydrate saturation as $\Lambda_{\mathrm{i}}^{*}=\left(1-\sqrt{S_{h}}\right) / 2$ when $S_{\mathrm{h}}$ $>0$ in a general trend (the blue dot curve in Figure 4(d)), and normalized maximum hydraulic diameter can be generally depicted by using $\Lambda_{\mathrm{h}}{ }^{*}=1-\sqrt{S_{\mathrm{h}}}$ (Figure $4(\mathrm{f})$ ).

An empirical model $\Lambda_{\mathrm{e}, \mathrm{i}, \mathrm{h}}{ }^{*}=1-(1-m) \sqrt{S_{\mathrm{h}}}-m S_{\mathrm{h}}{ }^{n}[23$, 37 is applied to fit values of different normalized maximum pore diameters, and values of empirical parameters are summarized in Figure 4(g). The empirical model is an alternative form for the weighted average of theoretical models $1-\sqrt{S_{h}}$ for pore-filling hydrates and $\sqrt{1-S_{h}}$ for grain-coating hydrates [23]. Values of empirical parameters $m$ and $n$ are largely controlled by hydrate pore habits. For grain-coating hydrates, the normalized maximum equivalent diameter of fluid-occupied pores can be described by setting $m=0.067$ and $n=70.6$, normalized maximum incircle diameter by setting $m=0.71$ and $n=5.98$, and normalized maximum hydraulic diameter by setting $m=0.51$ and $n=19.4$. For pore-filling hydrates, the normalized maximum equivalent diameter of fluid-occupied pores can be described by setting $m=0.95$ and $n=0.70$, normalized maximum incircle diameter by setting $m=0.55$ and $n=0.10$, and normalized maximum hydraulic diameter by setting $m=0.50$ and $n=0.79$.

\section{Discussion: Pore Shape Changes due to Hydrate Formation}

Fractal theory is widely used to characterize pore-scale structures and investigate various physical (e.g., hydraulic and electrical) properties of porous media $[49,50]$. In these investigations, pores within porous media are treated as circles with equivalent areas in the two-dimensional space, and the maximum equivalent diameter $\Lambda_{\mathrm{e}}$ can be calculated as [50]

$$
\Lambda_{\mathrm{e}}=\sqrt{\frac{4}{\pi} \frac{2-D_{\mathrm{f}}}{D_{\mathrm{f}}} \frac{\phi}{1-\phi} A_{\text {tot }}},
$$

where $A_{\text {tot }}$ is the total area of porous media, $\phi$ is porosity, and $D_{\mathrm{f}}$ is pore-size fractal dimension [28] which can be determined by using the box-counting method [51]. 


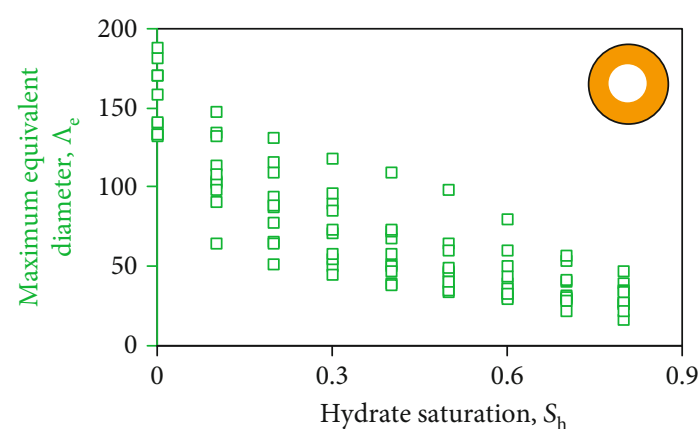

(a)

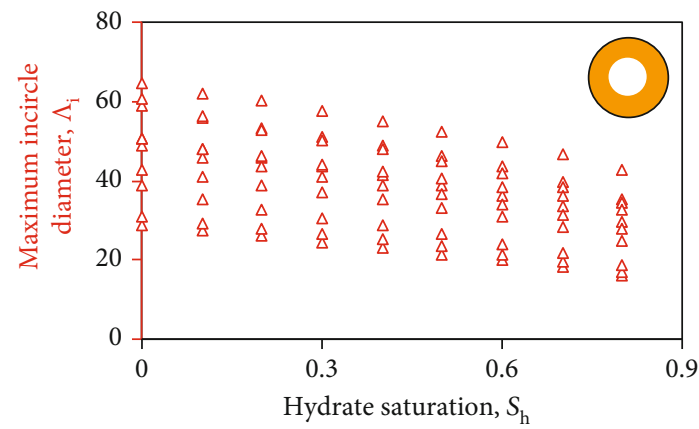

(c)

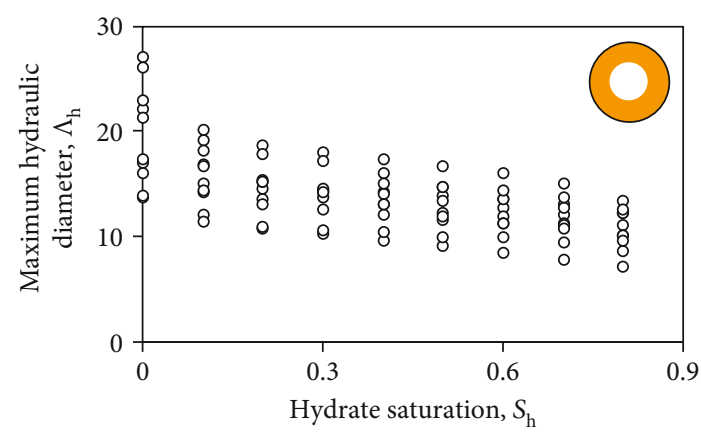

(e)

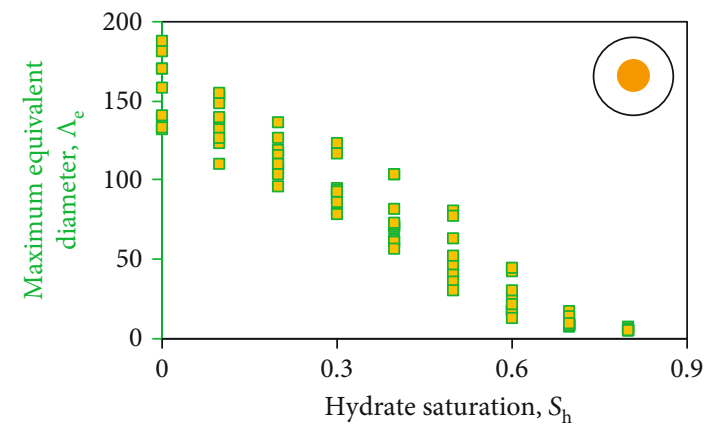

(b)

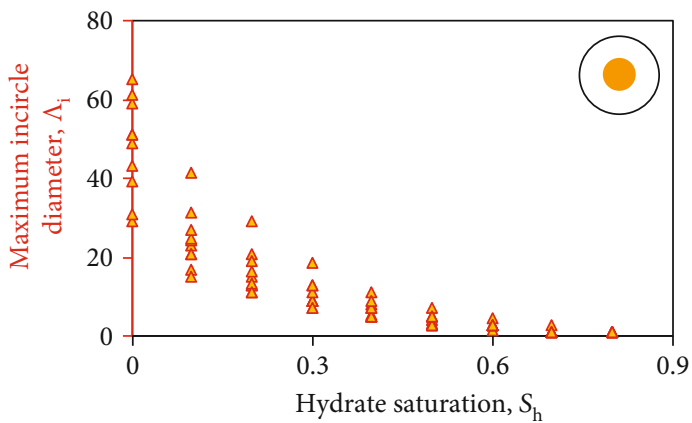

(d)

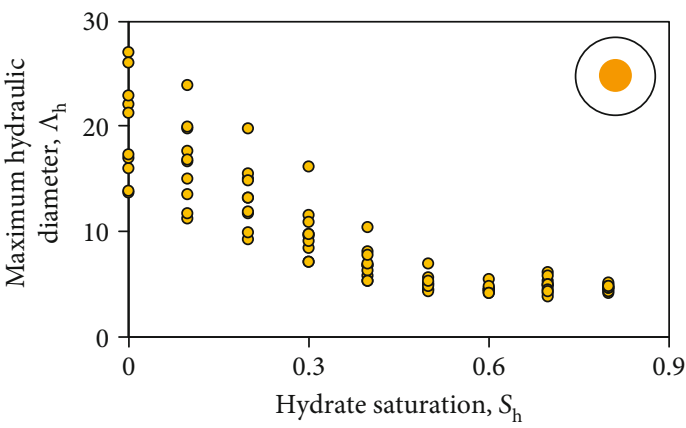

(f)

FIgURE 3: The maximum equivalent $\Lambda_{\mathrm{e}}$, incircle $\Lambda_{\mathrm{i}}$, and hydraulic $\Lambda_{\mathrm{h}}$ diameters of fluid-occupied pores within hydrate-bearing porous media evolving with hydrate saturation $S_{\mathrm{h}}$. The maximum equivalent diameter $\Lambda_{\mathrm{e}}$ for grain-coating (a) and pore-filling (b) hydrates. The maximum incircle diameter $\Lambda_{\mathrm{i}}$ for grain-coating (c) and pore-filling (d) hydrates. The maximum hydraulic diameter $\Lambda_{\mathrm{h}}$ for grain-coating (e) and porefilling (f) hydrates.

For the case that size of a pore within porous media is quantified by using incircle diameter $\lambda_{\mathrm{i}}$ (Figure 5(a)), area $A_{\mathrm{p}}$ of the pore can be calculated as

$$
\mathrm{A}_{\mathrm{p}}=c_{\mathrm{i}} \pi\left(\frac{\lambda_{\mathrm{i}}}{2}\right)^{2}
$$

and $c_{\mathrm{i}}$ is a geometry factor for incircle diameter. For references, the geometry factor for incircle diameter $c_{\mathrm{i}}=4 / \pi$ for square-shaped pores, $c_{i}=(3 \sqrt{2}) / \pi$ for regular triangleshaped pores, and $c_{\mathrm{i}}=1$ for circular pores. Then, the maximum incircle diameter $\Lambda_{\mathrm{i}}$ can be easily calculated as

$$
\Lambda_{\mathrm{i}}=\sqrt{\frac{1}{c_{\mathrm{i}}} \frac{4}{\pi} \frac{2-D_{\mathrm{f}}}{D_{\mathrm{f}}} \frac{\phi}{1-\phi} A_{\mathrm{tot}} .}
$$

If hydraulic diameter $\lambda_{\mathrm{h}}$ is used to quantify sizes of pores within porous media (Figure 5(a)), area $A_{\mathrm{p}}$ of an individual pore can be calculated as

$$
A_{\mathrm{p}}=c_{\mathrm{h}} \pi\left(\frac{\lambda_{\mathrm{h}}}{2}\right)^{2}
$$

and $c_{\mathrm{h}}$ is a geometry factor for hydraulic diameter. For references, the geometry factor for hydraulic diameter $c_{\mathrm{h}}=4 / \pi$ for square-shaped pores, $c_{\mathrm{h}}=(3 \sqrt{3}) / \pi$ for regular triangleshaped pores, and $c_{\mathrm{h}}=1$ for circular pores. Then, the maximum hydraulic diameter $\Lambda_{\mathrm{h}}$ can be easily calculated as

$$
\Lambda_{\mathrm{h}}=\sqrt{\frac{1}{c_{\mathrm{h}}} \frac{4}{\pi} \frac{2-D_{\mathrm{f}}}{D_{\mathrm{f}}} \frac{\phi}{1-\phi} A_{\mathrm{tot}} .}
$$




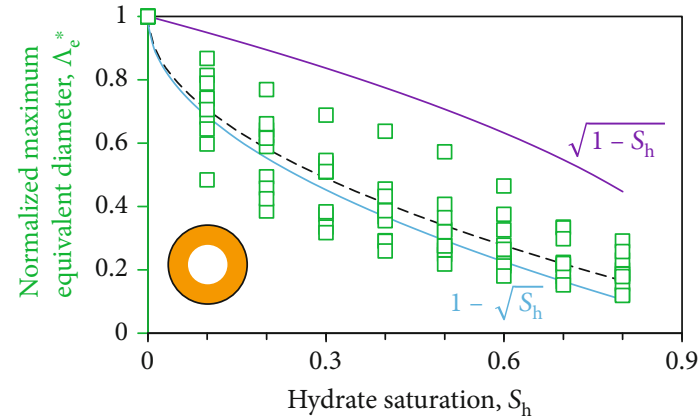

(a)

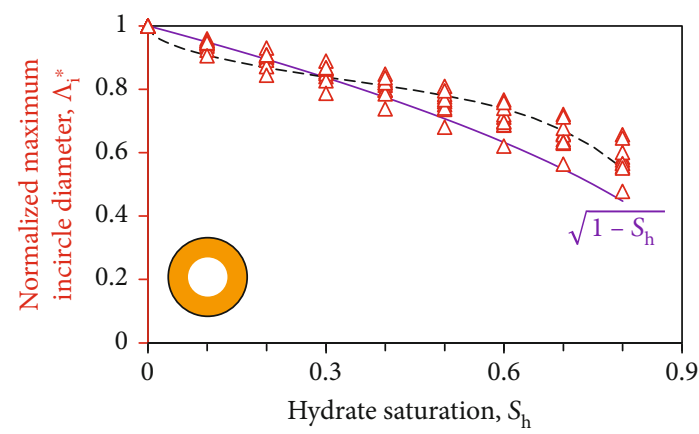

(c)

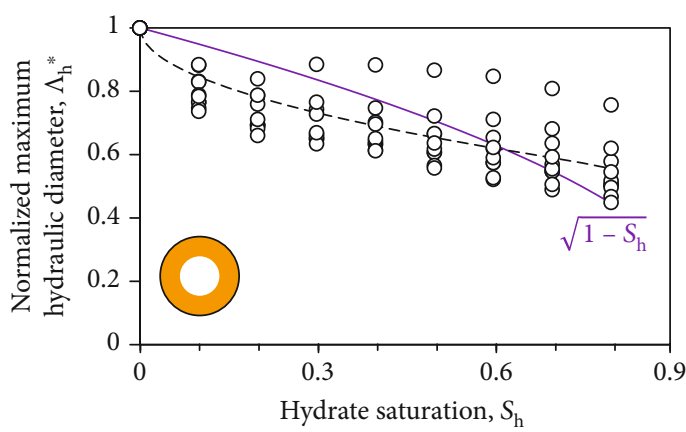

(e)

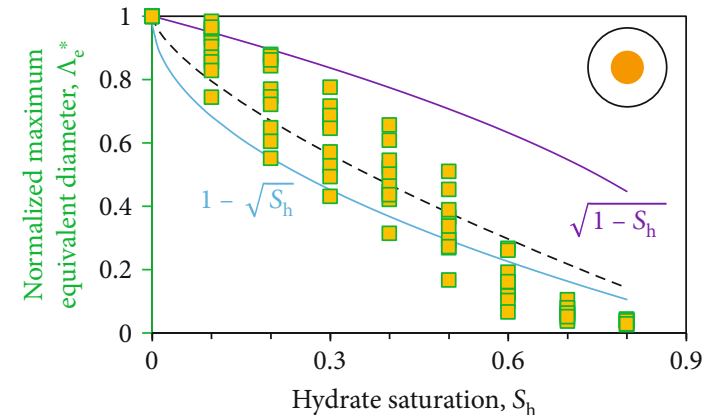

(b)

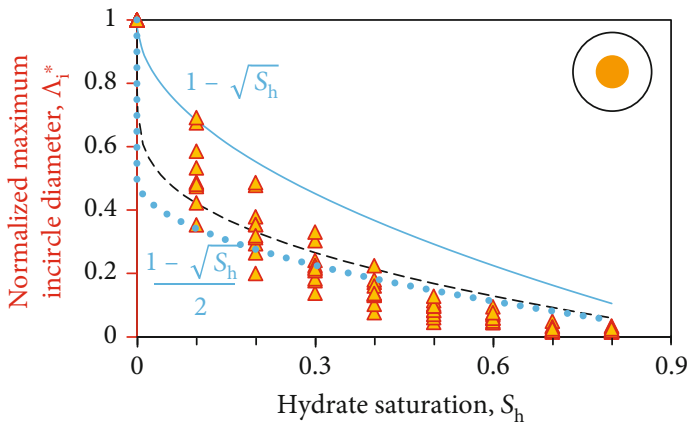

(d)

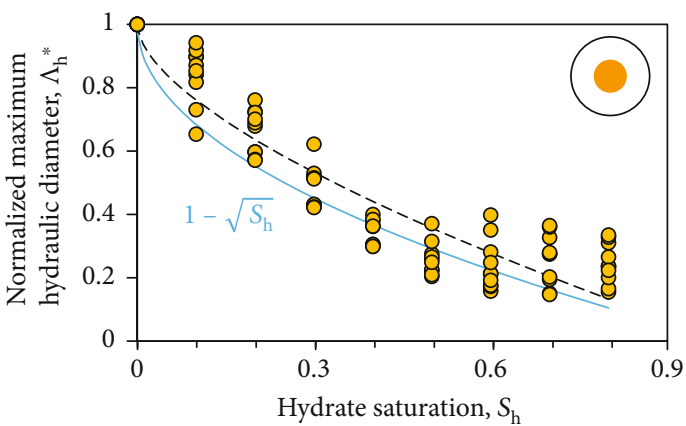

(f)

\begin{tabular}{|c|c|c|c|c|c|c|}
\hline \multirow{3}{*}{$\begin{array}{l}\text { Fitting model } \\
\text { Hydrate behaviors } \\
\text { Model parameters }\end{array}$} & \multicolumn{6}{|c|}{$\Lambda^{*}=1-(1-m) \sqrt{S_{\mathrm{h}}}-m S_{\mathrm{h}}^{\mathrm{n}}$} \\
\hline & \multicolumn{3}{|c|}{ Grain-coating hydrates } & \multicolumn{3}{|c|}{ Pore-filling hydrates } \\
\hline & $m$ & $n$ & $R^{2}$ & $m$ & $n$ & $R^{2}$ \\
\hline Equivalent diameter & 0.067 & 70.6 & 0.8817 & 0.95 & 0.70 & 0.8832 \\
\hline Incircle diameter & 0.71 & 5.98 & 0.9148 & 0.55 & 0.10 & 0.9340 \\
\hline Hydraulic diameter & 0.51 & 19.4 & 0.7158 & 0.50 & 0.79 & 0.8784 \\
\hline
\end{tabular}

(g)

Figure 4: Normalized maximum equivalent $\Lambda_{\mathrm{e}}{ }^{*}$, incircle $\Lambda_{\mathrm{i}}{ }^{*}$, and hydraulic $\Lambda_{\mathrm{h}}{ }^{*}$ diameters of fluid-occupied pores within hydrate-bearing porous media evolving with hydrate saturation $S_{\mathrm{h}}$. Normalized maximum equivalent diameter $\Lambda_{\mathrm{e}}{ }^{*}$ for grain-coating (a) and pore-filling (b) hydrates. Normalized maximum incircle diameter $\Lambda_{i}^{*}$ for grain-coating (c) and pore-filling (d) hydrates. The blue solid dot curve in (d) is drawn by $\Lambda_{\mathrm{i}}{ }^{*}=\left(1-\sqrt{S_{\mathrm{h}}}\right) / 2$ when $S_{\mathrm{h}}>0$ and $\Lambda_{\mathrm{i}}{ }^{*}=1$ when $S_{\mathrm{h}}=0$. Normalized maximum hydraulic diameter $\Lambda_{\mathrm{h}}{ }^{*}$ for grain-coating (e) and pore-filling (f) hydrates. (g) A fitting model and its parameter values for descriptions of different pore diameters changing with hydrate saturation. The fitting model is drawn as black dashed curves in (a-f).

If grain-coating hydrates uniformly grow in pores with different sizes and do not alter the shape of fluid-occupied pores (Figure 5(b)), area $A_{\mathrm{pc}}$, incircle $\lambda_{\mathrm{ic}}$, and hydraulic $\lambda_{\mathrm{hc}}$ diameters of these pores decrease with increasing hydrate saturation $S_{\mathrm{h}}$ as $A_{\mathrm{pc}}=A_{\mathrm{p} 0}\left(1-S_{\mathrm{h}}\right), \lambda_{\mathrm{ic}}=\lambda_{\mathrm{i} 0} \sqrt{1-S_{\mathrm{h}}}$, and $\lambda_{\mathrm{hc}}=$ $\lambda_{\mathrm{i} 0} \sqrt{1-S_{\mathrm{h}}}$, respectively. In these equations, subscript 0 


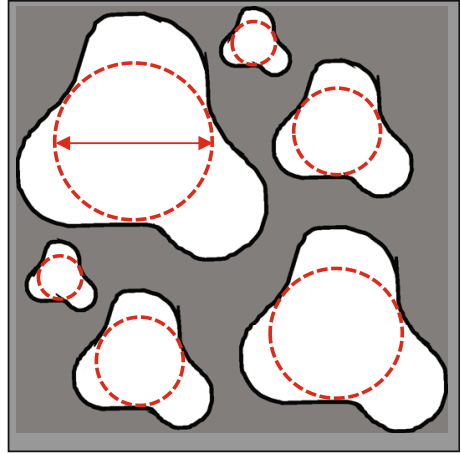

(a)

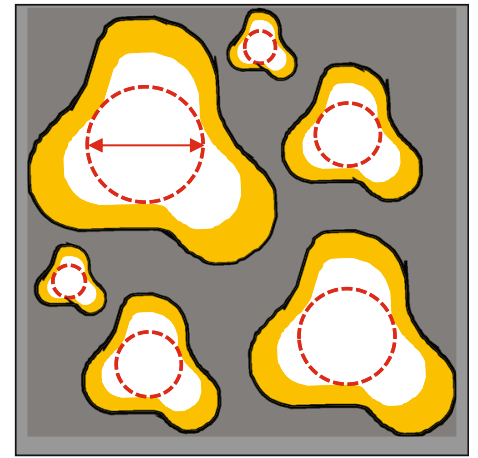

(b)

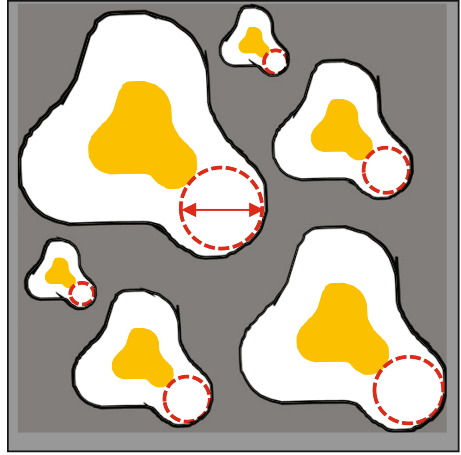

(c)

FIGURE 5: Irregularly shaped pores within hydrate-free and hydrate-bearing porous media. Gray color stands for solid particle, white for fluidoccupied pores, and yellow for gas hydrates. Red dashed circles represent incircles quantifying fluid-occupied pores. (a) Irregularly shaped pores with different sizes in hydrate-free porous media. (b) Irregularly shaped pores in porous media containing grain-coating hydrates. Gas hydrates uniformly grow in all pores with different sizes, and the shape of fluid-occupied pores before and after hydrate formation is unchanged. (c) Irregularly shaped pores in porous media containing pore-filling hydrates. Gas hydrates uniformly grow in all pores with different sizes, and the shape of solid hydrates is identical with that of intrinsic pores within porous media.

represents the intrinsic (i.e., hydrate-free) condition and subscript $\mathrm{c}$ stands for grain-coating hydrates. Then, it is easy to obtain

$$
c_{\mathrm{ic}}=c_{\mathrm{i} 0} \text {, }
$$

according to Equation (2), and

$$
c_{\mathrm{hc}}=c_{\mathrm{h} 0},
$$

based on Equation (4). Normalized geometry factor $c_{\mathrm{ic}}{ }^{*}$ for incircle diameter in porous media containing grain-coating hydrates can be defined as

$$
c_{\mathrm{ic}}^{*}=\frac{c_{\mathrm{ic}}}{c_{\mathrm{i} 0}}=1
$$

according to Equation (6), and normalized geometry factor $c_{\mathrm{hc}}{ }^{*}$ for hydraulic diameter as

$$
c_{\mathrm{hc}}^{*}=\frac{c_{\mathrm{hc}}}{c_{\mathrm{h} 0}}=1,
$$

according to Equation (7).

If pore-filling hydrates uniformly grow in pores with different sizes and the hydrate shape is identical with the intrinsic pore shape (Figure 5(c)), area $A_{\mathrm{pf}}$, incircle $\lambda_{\mathrm{if}}$, and hydraulic $\lambda_{\mathrm{hf}}$ diameters of these pores decrease with increasing hydrate saturation $S_{\mathrm{h}}$ as $A_{\mathrm{pf}}=A_{\mathrm{p} 0}\left(1-S_{\mathrm{h}}\right), \lambda_{\mathrm{if}}=\lambda_{\mathrm{i} 0}(1-$ $\left.\sqrt{S_{\mathrm{h}}}\right) / 2$, and $\lambda_{\mathrm{hc}}=\lambda_{\mathrm{i} 0}\left(1-\sqrt{S_{\mathrm{h}}}\right)$, respectively. In these equations, subscript $f$ represents pore-filling hydrates. Then, it is easy to obtain

$$
c_{\mathrm{if}}=\frac{4\left(1+\sqrt{S_{\mathrm{h}}}\right)}{1-\sqrt{S_{\mathrm{h}}}} c_{\mathrm{i} 0}
$$

according to Equation (2), and

$$
c_{\mathrm{hf}}=\frac{1+\sqrt{S_{\mathrm{h}}}}{1-\sqrt{S_{\mathrm{h}}}} c_{\mathrm{h} 0},
$$

based on Equation (4). Equation (10) is applicable for $S_{\mathrm{h}}>0$, and $c_{\text {if }}=c_{\mathrm{i} 0}$ when $S_{\mathrm{h}}=0$. Normalized geometry factor $c_{\mathrm{if}}{ }^{*}$ for incircle diameter in porous media containing pore-filling hydrates can be defined as

$$
c_{\mathrm{if}}^{*}=\frac{c_{\mathrm{if}}}{c_{\mathrm{i} 0}}=\frac{4\left(1+\sqrt{S_{\mathrm{h}}}\right)}{1-\sqrt{S_{\mathrm{h}}}}, \quad S_{\mathrm{h}}>0,
$$

according to Equation (10), and normalized geometry factor $c_{\mathrm{hf}}{ }^{*}$ for hydraulic diameter as

$$
c_{\mathrm{hf}}^{*}=\frac{c_{\mathrm{hf}}}{c_{\mathrm{h} 0}}=\frac{1+\sqrt{S_{\mathrm{h}}}}{1-\sqrt{S_{\mathrm{h}}}}
$$

according to Equation (11).

Values of the pore-size fractal dimension for fluidoccupied pores within porous media containing graincoating and pore-filling hydrates are summarized in Tables 1 and 2, respectively. The pore diameter ratio $\beta$ defined as the ratio of the minimum over maximum pore diameters can be calculated by [52]

$$
\beta=\phi^{1 /\left(2-D_{\mathrm{f}}\right)},
$$

and values of the pore diameter ratio within porous media containing grain-coating and pore-filling hydrates are shown in Figure 6. It is obvious that all the $\beta$ values are generally smaller than $1.0 \times 10^{-2}$, and the fractal theory can be used to analyze properties of porous media containing gas hydrates in this study [52].

Values of geometry factor $c_{\mathrm{i}}$ for incircle diameter within hydrate-bearing porous media can be calculated by using Equations (3), where $A_{\text {tot }}=300 \times 300 \mathrm{px}^{2}$. Geometry factors 


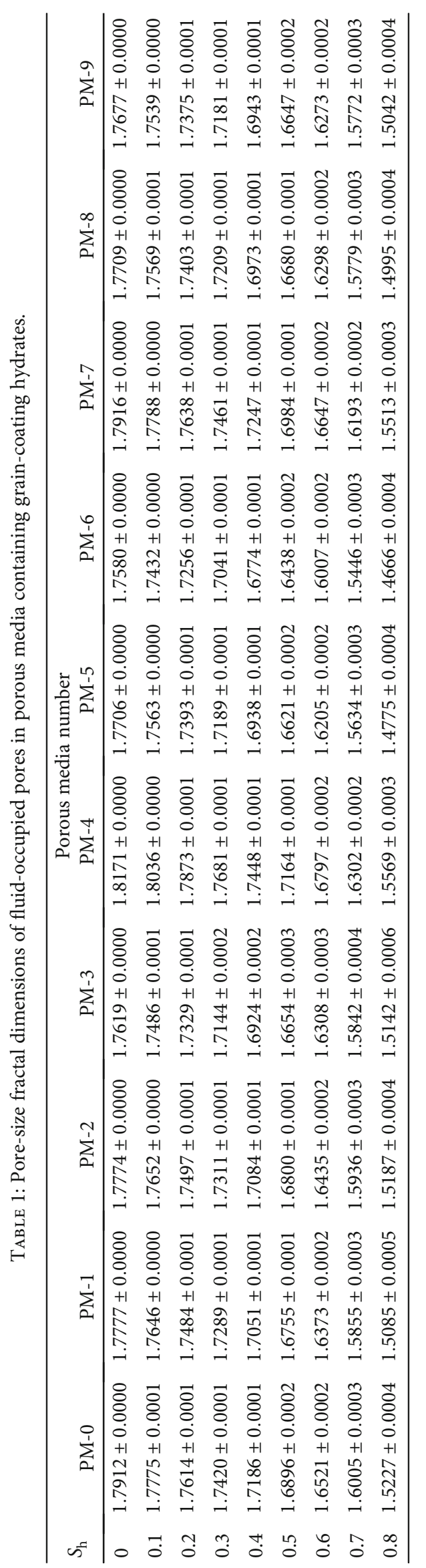




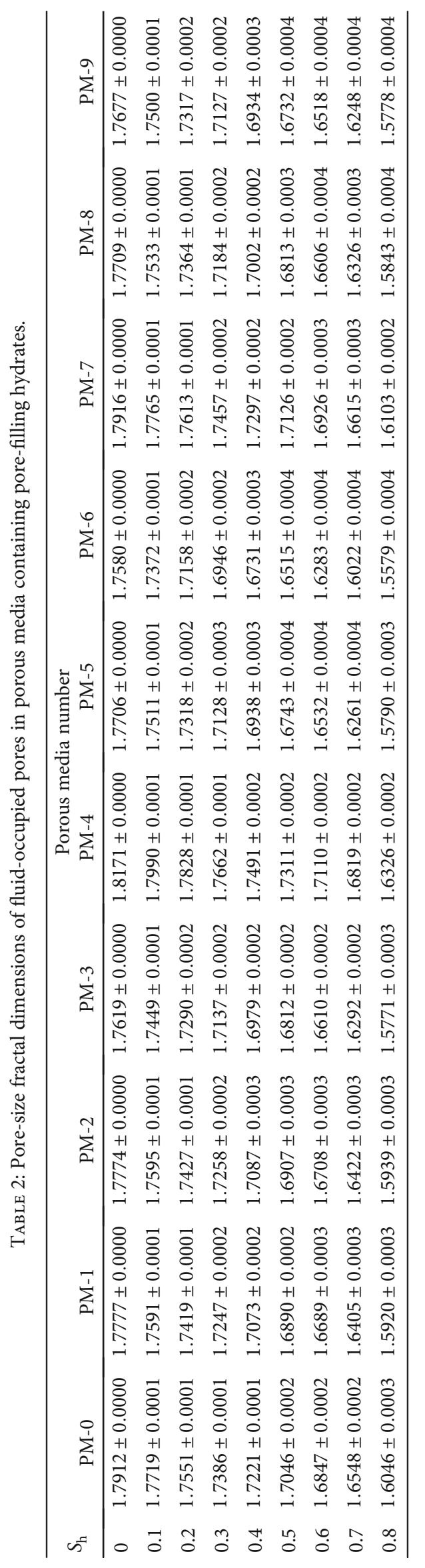




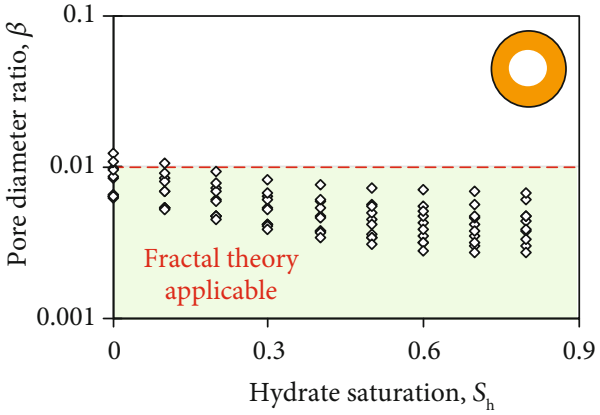

(a)

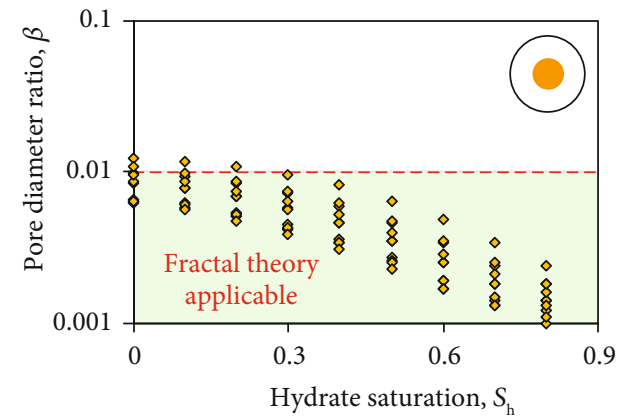

(b)

FIGURE 6: Pore diameter ratio $\beta$ changing due to the presence of grain-coating (a) and pore-filling (b) hydrates within porous media. Regions colored in light green represent fractal theory applicable conditions (i.e., $\beta<1.0 \times 10^{-2}$ ).

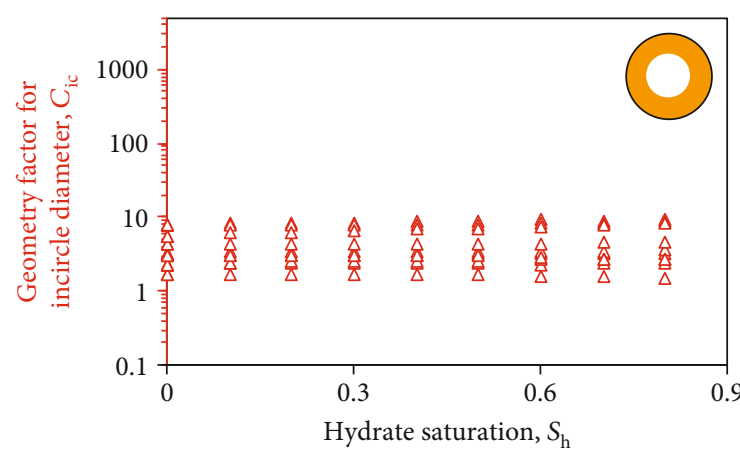

(a)

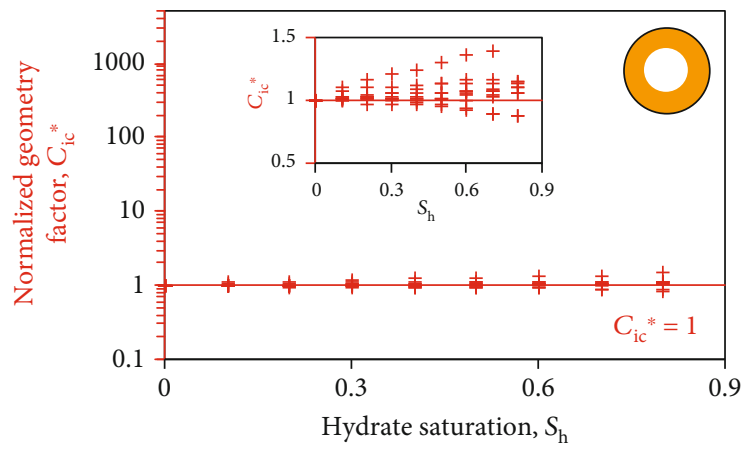

(c)

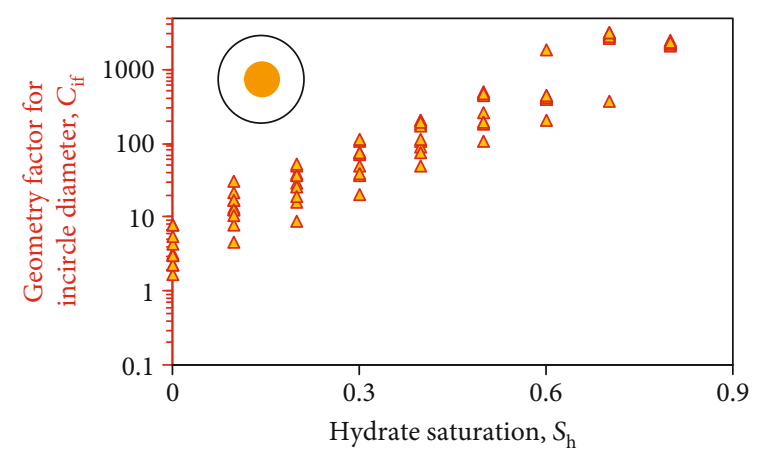

(b)

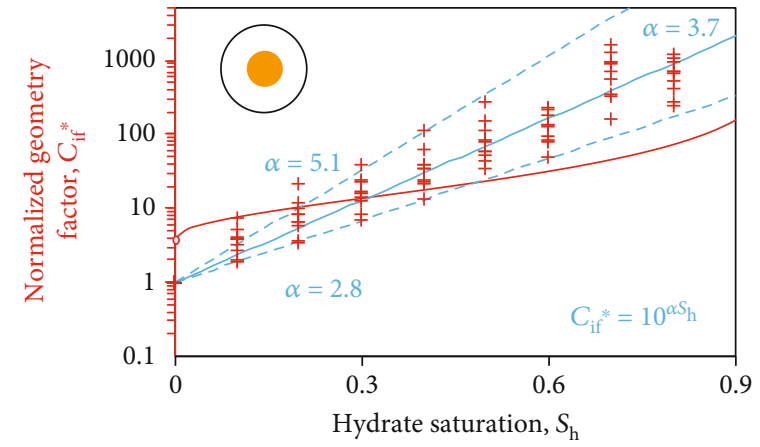

(d)

FIGURE 7: Geometry factors $c_{\mathrm{i}}$ and normalized geometry factors $c_{\mathrm{i}}{ }^{*}$ for incircle diameter evolving with hydrate saturation $S_{\mathrm{h}}$. (a) Geometry factor for incircle diameter $c_{\mathrm{ic}}$ in porous media containing grain-coating hydrates. (b) Geometry factor for incircle diameter $c_{\text {if }}$ in porous media containing pore-filling hydrates. (c) Normalized geometry factor for incircle diameter $c_{\mathrm{ic}}{ }^{*}$ in porous media containing grain-coating hydrates. (d) Normalized geometry factor for incircle diameter $c_{\mathrm{if}}{ }^{*}$ in porous media containing pore-filling hydrates. The red curve is drawn by $c_{\mathrm{if}}{ }^{*}=4\left(1+\sqrt{S_{\mathrm{h}}}\right) /\left(1-\sqrt{S_{\mathrm{h}}}\right)$ when $S_{\mathrm{h}}>0$, and $c_{\mathrm{if}}{ }^{*}=1$ at $S_{\mathrm{h}}=0$.

for incircle diameter changing due to the presence of graincoating and pore-filling hydrates are shown in Figures 7(a) and $7(\mathrm{~b})$, respectively. It is obvious that hydrate saturation $S_{\mathrm{h}}$ has little effects on $c_{\mathrm{ic}}$ values compared with $c_{\text {if }}$ values. The normalized geometry factor for incircle diameter changing due to the presence of grain-coating hydrates is shown in Figure $7(\mathrm{c})$ and pore-filling hydrates in Figure $7(\mathrm{~d})$. It is shown that $c_{\mathrm{ic}}{ }^{*}$ values generally stay close to the horizontal red line $c_{\mathrm{ic}}{ }^{*}=1$ (Figure $7(\mathrm{c})$ ), and $c_{\mathrm{if}}{ }^{*}$ values go through an evolutionary process from below to above the red curve $c_{\mathrm{if}}{ }^{*}=4\left(1+\sqrt{S_{\mathrm{h}}}\right) / 1-\sqrt{S_{\mathrm{h}}}$ (Figure $\left.7(\mathrm{~d})\right)$. These discrepancies between numerical simulated $c_{\mathrm{ic}, \mathrm{f}}{ }^{*}$ data and corresponding theoretical models (i.e., Equations (8) and (12)) are mainly due to differences in hydrate pore habits since grain-coating and pore-filling hydrate growths can hardly follow the uniform and self-similar way (Figure 5) strictly. Based on simulated data, an empirical model is proposed as

$$
c_{\text {if }}^{*}=10^{\alpha S_{\mathrm{h}}}
$$

to depict how $c_{\mathrm{if}}{ }^{*}$ values evolve with hydrate saturation. Equation (15) with $\alpha=3.7$ can capture the essential physics of pore 


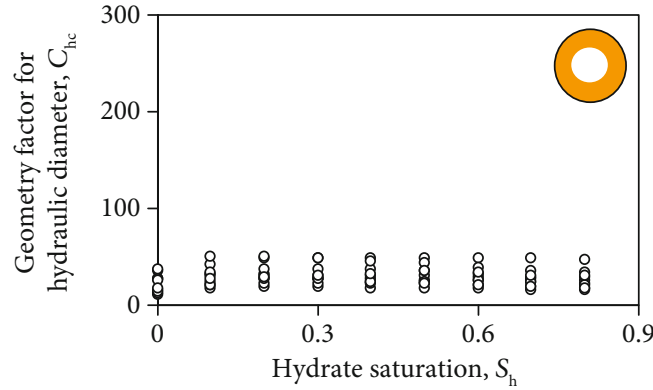

(a)

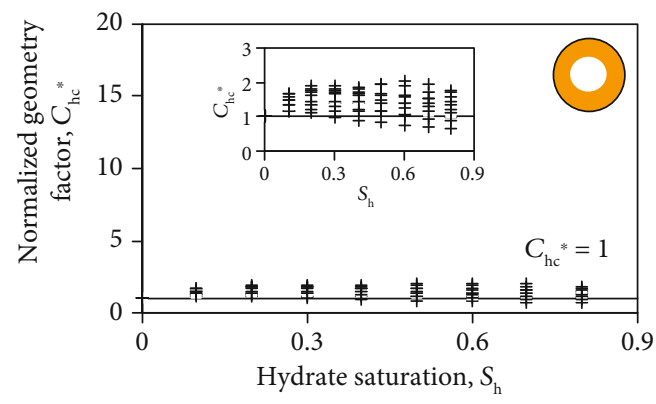

(c)

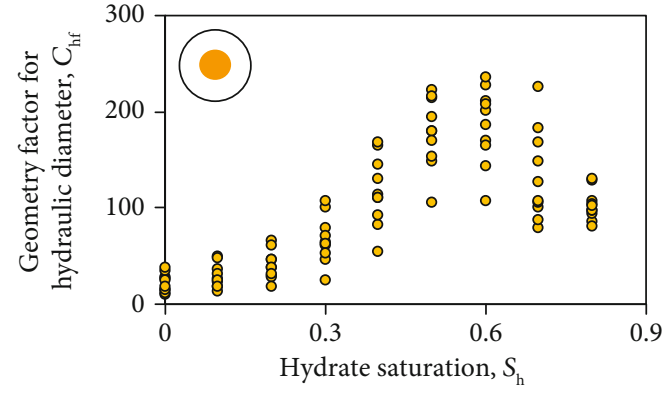

(b)

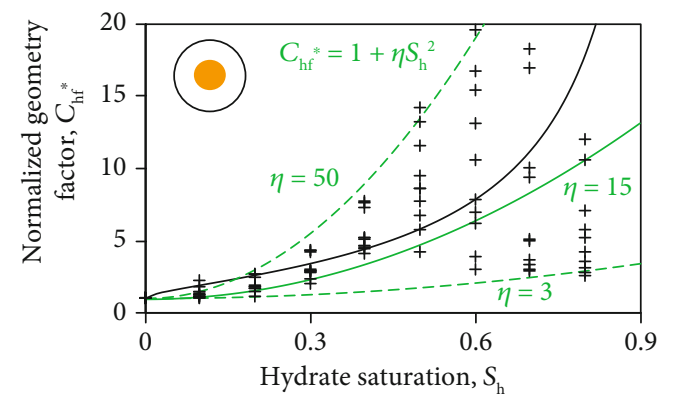

(d)

FIgURE 8: Geometry factors $c_{\mathrm{h}}$ and normalized geometry factors $c_{\mathrm{h}}{ }^{*}$ for hydraulic diameter evolving with hydrate saturation $S_{\mathrm{h}}$. (a) Geometry factor for hydraulic diameter $c_{\mathrm{hc}}$ in porous media containing grain-coating hydrates. (b) Geometry factor for hydraulic diameter $c_{\mathrm{hf}}$ in porous media containing pore-filling hydrates. (c) Normalized geometry factor for hydraulic diameter $c_{\mathrm{hc}}{ }^{*}$ in porous media containing grain-coating hydrates. (d) Normalized geometry factor for hydraulic diameter $c_{\mathrm{hf}}{ }^{*}$ in porous media containing pore-filling hydrates. The black curve is drawn by $c_{\mathrm{hf}}{ }^{*}=\left(1+\sqrt{S_{\mathrm{h}}}\right) /\left(1-\sqrt{S_{\mathrm{h}}}\right)$.

shape changes in hydrate-bearing porous media during hydrate formation, while $\alpha=2.8$ and $\alpha=5.1$ set the lower and upper bounds.

Geometry factors $c_{\mathrm{h}}$ and normalized geometry factors ${c_{\mathrm{h}}}^{*}$ for hydraulic diameter evolving with hydrate saturation $S_{\mathrm{h}}$ are shown in Figure 8. It is obvious that hydrate saturation and morphology effects on $c_{\mathrm{i}}$ and $c_{\mathrm{i}}{ }^{*}$ values are similar with those on $c_{\mathrm{h}}$ and $c_{\mathrm{h}}{ }^{*}$ values. Normalized geometry factor $c_{\mathrm{hc}}{ }^{*}$ for hydraulic diameter in porous media containing grain-coating hydrates changes much more mildly compared with normalized geometry factor $c_{\mathrm{hf}}{ }^{*}$. The black curve in Figure 8(d) drawn by using Equation (13) agrees well with the general trend of $c_{\mathrm{hf}}{ }^{*}$ values increasing due to the presence of pore-filling hydrates. Based on simulated data, another empirical model is proposed for the normalized geometry factor $c_{\mathrm{if}}{ }^{*}$ prediction, which is

$$
c_{\mathrm{hf}}^{*}=1+\eta S_{\mathrm{h}}^{2},
$$

with $\eta=15$ describing the general trend, $\eta=3$ setting the lower bound, and $\eta=50$ setting the upper bound.

In general, grain-coating hydrates barely change while pore-filling hydrates significantly enhance $c_{\mathrm{ic}}{ }^{*}$ and $c_{\mathrm{hc}}{ }^{*}$ values, and perimeters of fluid-occupied pores decrease with an increase in grain-coating hydrate saturations but increase due to the presence of pore-filling hydrates according to their definitions. This implies that shapes of fluid-occupied pores do not obviously change due to the presence of grain- coating hydrates, but they alter to be more fiber-shaped when pore-filling hydrates occur.

\section{Conclusions}

This study numerically simulates random nucleation and growth of grain-coating and pore-filling hydrates within artificial two-dimensional porous media to quantify the maximum equivalent, incircle, and hydraulic diameters of fluidoccupied pores, and how maximum pore diameters evolve due to the presence of gas hydrates is analyzed. Theoretical and empirical models of geometry factors for incircle and hydraulic diameters of fluid-occupied pores are proposed based on fractal theory, and these proposed models together with simulated data are further applied to discuss effects of hydrate saturation and morphology on fluid-occupied pore shapes during hydrate formation. Main conclusions are drawn as follows.

Intrinsic porosity, host particle size, and sphericity not only have obvious effects on the intrinsic maximum equivalent, incircle, and hydraulic diameters of fluid-occupied pores within hydrate-free porous media but also lead to discrepancies in the maximum pore diameters even through hydrate saturation and morphology are seemly identical.

Hydrate pore habits have relatively minor effects on the maximum equivalent diameter of fluid-occupied pores decreasing with increasing hydrate saturation. However, pore-filling hydrates reduce the maximum incircle and hydraulic diameters of fluid-occupied pores much more 
significantly than grain-coating hydrates especially when hydrate saturation is higher. Values of normalized maximum equivalent diameter $\Lambda_{\mathrm{i}}{ }^{*}$ generally fall in the region limited by upper $\sqrt{1-S_{\mathrm{h}}}$ and lower $1-\sqrt{S_{\mathrm{h}}}$ bounds. The upper bound can capture the essential physics of normalized maximum incircle and hydraulic diameter reductions due to the presence of grain-coating hydrates, and the lower bound is generally consistent with values of normalized maximum hydraulic diameter during pore-filling hydrate formation. In addition, values of normalized maximum incircle diameter $\Lambda_{\mathrm{i}}{ }^{*}$ during the pore-filling hydrate formation approach $\Lambda_{\mathrm{i}}{ }^{*}=\left(1-\sqrt{S_{\mathrm{h}}}\right) / 2$ especially when hydrate saturation is larger. The published empirical model $\Lambda^{*}=1-(1-m) \sqrt{S_{\mathrm{h}}}$ $-m S_{\mathrm{h}}{ }^{n}$ can be used to predict normalized maximum equivalent, incircle, and hydraulic diameters of fluid-occupied pores during hydrate formation.

Shapes of fluid-occupied pores change little due to the presence of grain-coating hydrates, and corresponding geometry factors for incircle and hydraulic diameters are generally unchanged during hydrate formation. On the contrary, pore-filling hydrates lead to significant variations in fluid-occupied pore shapes (i.e., more fibrous). Normalized geometry factor $c_{\text {iff }}{ }^{*}$ for incircle diameter increases with

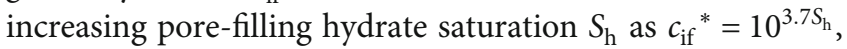
and normalized geometry factor $c_{\mathrm{hf}}{ }^{*}$ for hydraulic diameter increases as $c_{\mathrm{hf}}{ }^{*}=1+15 S_{\mathrm{h}}{ }^{2}$. Theoretical models $c_{\mathrm{if}}{ }^{*}=4(1+$ $\left.\sqrt{S_{\mathrm{h}}}\right) /\left(1-\sqrt{S_{\mathrm{h}}}\right)$ and $c_{\mathrm{hf}}{ }^{*}=\left(1+\sqrt{S_{\mathrm{h}}}\right) /\left(1-\sqrt{S_{\mathrm{h}}}\right)$ can capture the essential physics of geometry factor enhancements due to pore-filling hydrate formation.

In this study, how the maximum incircle pore diameter changes with increasing hydrate saturation has a potential to benefit two-dimensional pore network modeling of hydraulic properties, and conclusions about the maximum hydraulic diameter are able to facilitate capillary-bundlebased theoretical analyses.

\section{Data Availability}

All images of artificial porous media in this study can be downloaded from FigShare at https://figshare.com/articles/ Artificial_Porous_Media/11988594.

\section{Additional Points}

Key Points. (i) Effects of host particle properties on the maximum equivalent, incircle, and hydraulic diameters of fluidoccupied pores are analyzed. (ii) Similarities and differences in different maximum pore diameters of fluid-occupied pores changing with hydrate saturation are clarified. (iii) Variations of fluid-occupied pore shapes due to the presence of grain-coating and pore-filling hydrates are quantitatively characterized.

\section{Conflicts of Interest}

The authors declare that there is no conflict of interest regarding the publication of this paper.

\section{Acknowledgments}

This research is funded by the National Natural Science Foundation of China (Nos. 41872136 and 41876051), the Fundamental Research Funds for the Central Universities (China University of Geosciences, Wuhan) (No. CUGG C04), the Taishan Scholar Special Experts Project (No. ts201712079), the National Key Research and Development Project (No. 2018YFE0126400), and the China Geological Survey (No. DD20190221), and their supports are gratefully acknowledged.

\section{References}

[1] N. Vedachalam, S. Srinivasalu, G. Rajendran, G. A. Ramadass, and M. A. Atmanand, "Review of unconventional hydrocarbon resources in major energy consuming countries and efforts in realizing natural gas hydrates as a future source of energy," Journal of Natural Gas Science and Engineering, vol. 26, pp. 163-175, 2015.

[2] R. Boswell and T. S. Collett, "Current perspectives on gas hydrate resources," Energy \& Environmental Science, vol. 4, no. 4, pp. 1206-1215, 2011.

[3] R. A. Kerr, "Gas hydrate resource: smaller but sooner," Science, vol. 303, no. 5660, pp. 946-947, 2004.

[4] D. Cyranoski, "Japanese test coaxes fire from ice," Nature: International Weekly Journal of Science, vol. 496, no. 7446, p. 409, 2013.

[5] M. Terzariol, G. Goldsztein, and J. C. Santamarina, "Maximum recoverable gas from hydrate bearing sediments by depressurization," Energy, vol. 141, pp. 1622-1628, 2017.

[6] S. Uchida, J. S. Lin, E. M. Myshakin, Y. Seol, and R. Boswell, "Numerical simulations of sand migration during gas production in hydrate-bearing sands interbedded with thin mud layers at site NGHP-02-16," Marine and Petroleum Geology, vol. 108, pp. 639-647, 2019.

[7] R. Boswell, E. Myshakin, G. Moridis et al., "India National Gas Hydrate Program Expedition 02 summary of scientific results: numerical simulation of reservoir response to depressurization," Marine and Petroleum Geology, vol. 108, pp. 154-166, 2019.

[8] L. Liu, X. Lu, X. Zhang, C. Liu, and B. Du, "Numerical simulations for analyzing deformation characteristics of hydratebearing sediments during depressurization," Advances in Geo-Energy Research, vol. 1, no. 3, pp. 135-147, 2017.

[9] Y. Li, F. Ning, N. Wu et al., "Protocol for sand control screen design of production wells for clayey silt hydrate reservoirs: a case study," Energy Science and Engineering, vol. 8, no. 5, pp. 1438-1449, 2020.

[10] L. Liu, X. Lu, and X. Zhang, "A theoretical model for predicting the spatial distribution of gas hydrate dissociation under the combination of depressurization and heating without the discontinuous interface assumption," Journal of Petroleum Science and Engineering, vol. 133, pp. 589-601, 2015.

[11] L. Huang, Z. Su, N. Wu, and J. Cheng, "Analysis on geologic conditions affecting the performance of gas production from hydrate deposits," Marine and Petroleum Geology, vol. 77, pp. 19-29, 2016.

[12] T. Ajayi, B. J. Anderson, Y. Seol, R. Boswell, and E. M. Myshakin, "Key aspects of numerical analysis of gas hydrate reservoir performance: Alaska North Slope Prudhoe Bay Unit "L-Pad" 
hydrate accumulation," Journal of Natural Gas Science and Engineering, vol. 51, pp. 37-43, 2018.

[13] H. Singh, N. Mahabadi, E. M. Myshakin, and Y. Seol, "A mechanistic model for relative permeability of gas and water flow in hydrate-bearing porous media with capillarity," Water Resources Research, vol. 55, no. 4, pp. 3414-3432, 2019.

[14] S. Dai, J. Kim, Y. Xu et al., "Permeability anisotropy and relative permeability in sediments from the National Gas Hydrate Program Expedition 02, offshore India," Marine and Petroleum Geology, vol. 108, pp. 705-713, 2019.

[15] X. Y. Chen, R. Verma, D. N. Espinoza, and M. Prodanovic, "Pore-scale determination of gas relative permeability in hydrate-bearing sediments using X-ray computed microtomography and lattice Boltzmann method," Water Resources Research, vol. 54, no. 1, pp. 600-608, 2018.

[16] N. Mahabadi, S. Dai, Y. Seol, T. Sup Yun, and J. Jang, “The water retention curve and relative permeability for gas production from hydrate-bearing sediments: pore-network model simulation," Geochemistry, Geophysics, Geosystems, vol. 17, no. 8, pp. 3099-3110, 2016.

[17] S. Dai and Y. Seol, "Water permeability in hydrate-bearing sediments: a pore-scale study," Geophysical Research Letters, vol. 41, no. 12, pp. 4176-4184, 2014.

[18] S. Dai and J. C. Santamarina, "Water retention curve for hydrate-bearing sediments," Geophysical Research Letters, vol. 40, pp. 1-5, 2013.

[19] H. Minagawa, Y. Nishikawa, I. Ikeda et al., "Characterization of sand sediment by pore size distribution and permeability using proton nuclear magnetic resonance measurement," Journal of Geophysical Research, vol. 113, no. B7, 2008.

[20] J. Katagiri, Y. Konno, J. Yoneda, and N. Tenma, "Pore-scale modeling of flow in particle packs containing grain-coating and pore-filling hydrates: verification of a Kozeny-Carmanbased permeability reduction model," Journal of Natural Gas Science and Engineering, vol. 45, pp. 537-551, 2017.

[21] D. Wang, Y. Li, C. Liu et al., "Study of hydrate occupancy, morphology and microstructure evolution with hydrate dissociation in sediment matrices using X-ray micro-CT," Marine and Petroleum Geology, vol. 113, p. 104138, 2020.

[22] C. Li, C. Liu, G. Hu et al., "Investigation on the multiparameter of hydrate-bearing sands using nano-focus X-ray computed tomography," Journal of Geophysical Research: Solid Earth, vol. 124, no. 3, pp. 2286-2296, 2019.

[23] Z. Zhang, C. Li, F. Ning et al., "Pore fractal characteristics of hydrate-bearing sands and implications to the saturated water permeability," Journal of Geophysical Research: Solid Earth, vol. 125, no. 3, 2020.

[24] J. Wang, J. Zhao, M. Yang, Y. Li, W. Liu, and Y. Song, "Permeability of laboratory-formed porous media containing methane hydrate: observations using X-ray computed tomography and simulations with pore network models," Fuel, vol. 145, pp. 170-179, 2015.

[25] S. Tian, W. Ren, G. Li, R. Yang, and T. Wang, "A theoretical analysis of pore size distribution effects on shale apparent permeability," Geofluids, vol. 2017, Article ID 7492328, 9 pages, 2017.

[26] N. Nishiyama and T. Yokoyama, "Permeability of porous media: role of the critical pore size," Journal of Geophysical Research: Solid Earth, vol. 122, no. 9, pp. 6955-6971, 2017.

[27] J. Cai, Z. Zhang, W. Wei, D. Guo, S. Li, and P. Zhao, "The critical factors for permeability-formation factor relation in reser- voir rocks: pore-throat ratio, tortuosity and connectivity," Energy, vol. 188, p. 116051, 2019.

[28] B. Yu and P. Cheng, "A fractal permeability model for bidispersed porous media," International Journal of Heat and Mass Transfer, vol. 45, no. 14, pp. 2983-2993, 2002.

[29] L. Liu, S. Dai, F. Ning, J. Cai, C. Liu, and N. Wu, "Fractal characteristics of unsaturated sands - implications to relative permeability in hydrate-bearing sediments," Journal of Natural Gas Science and Engineering, vol. 66, pp. 11-17, 2019.

[30] J. Cai and B. Yu, "Prediction of maximum pore size of porous media based on fractal geometry," Fractals, vol. 18, no. 4, pp. 417-423, 2011.

[31] A. G. Kostornov, L. E. Lunin, V. P. Semenets, and L. I. Chernyshev, "Comparative study of permeable materials from metal powders and fibers," Soviet Powder Metallurgy and Metal Ceramics, vol. 22, no. 3, pp. 199-201, 1983.

[32] R. Pitchumani and B. Ramakrishnan, "A fractal geometry model for evaluating permeabilities of porous preforms used in liquid composite molding," International Journal of Heat and Mass Transfer, vol. 42, no. 12, pp. 22192232, 1999.

[33] J. Wu and B. Yu, "A fractal resistance model for flow through porous media," International Journal of Heat and Mass Transfer, vol. 50, no. 19-20, pp. 3925-3932, 2007.

[34] C. Liu, Q. Meng, X. He et al., "Characterization of natural gas hydrate recovered from Pearl River Mouth basin in South China Sea," Marine and Petroleum Geology, vol. 61, Supplement C, pp. 14-21, 2015.

[35] T. Ito, Y. Komatsu, T. Fujii et al., "Lithological features of hydrate-bearing sediments and their relationship with gas hydrate saturation in the eastern Nankai Trough, Japan," Marine and Petroleum Geology, vol. 66, Part 2, pp. 368-378, 2015.

[36] M. Oshima, K. Suzuki, J. Yoneda et al., "Lithological properties of natural gas hydrate-bearing sediments in pressure- cores recovered from the Krishna-Godavari Basin," Marine and Petroleum Geology, vol. 108, pp. 439-470, 2019.

[37] L. Liu, Z. Zhang, C. Li et al., "Hydrate growth in quartzitic sands and implication of pore fractal characteristics to hydraulic, mechanical, and electrical properties of hydrate-bearing sediments," Journal of Natural Gas Science and Engineering, vol. 75, p. 103109, 2020.

[38] J. Cai, E. Perfect, C.-L. Cheng, and X. Hu, "Generalized modeling of spontaneous imbibition based on Hagen-Poiseuille flow in tortuous capillaries with variably shaped apertures," Langmuir, vol. 30, no. 18, pp. 5142-5151, 2014.

[39] M. Tuller, D. Or, and L. M. Dudley, “Adsorption and capillary condensation in porous media: liquid retention and interfacial configurations in angular pores," Water Resources Research, vol. 35, no. 7, pp. 1949-1964, 1999.

[40] G. Mason and N. R. Morrow, "Capillary behavior of a perfectly wetting liquid in irregular triangular tubes," Journal of Colloid and Interface Science, vol. 141, no. 1, pp. 262-274, 1991.

[41] S. Jiang, Y. Kang, and Z. Sun, "A digital image method for analysis of soil pores," in IFIP International Federation for Information Processing, pp. 1029-1038, Boston, Massachusetts, USA, 2009.

[42] G. Breyiannis, S. Varoutis, and D. Valougeorgis, "Rarefied gas flow in concentric annular tube: estimation of the Poiseuille number and the exact hydraulic diameter," European Journal of Mechanics - B/Fluids, vol. 27, no. 5, pp. 609-622, 2008. 
[43] D. Silin and T. Patzek, "Pore space morphology analysis using maximal inscribed spheres," Physica A: Statistical Mechanics and its Applications, vol. 371, no. 2, pp. 336-360, 2006.

[44] A. Golparvar, Y. Zhou, K. Wu, J. Ma, and Z. Yu, "A comprehensive review of pore scale modeling methodologies for multiphase flow in porous media," Advances in Geo-Energy Research, vol. 2, no. 4, pp. 418-440, 2018.

[45] B. Dietrich, W. Schabel, M. Kind, and H. Martin, "Pressure drop measurements of ceramic sponges-Determining the hydraulic diameter," Chemical Engineering Science, vol. 64, no. 16, pp. 3633-3640, 2009.

[46] A. M. Lewis, "Measuring the hydraulic diameter of a pore or conduit," American Journal of Botany, vol. 79, no. 10, pp. 1158-1161, 1992.

[47] A. Koponen, M. Kataja, and J. Timonen, "Tortuous flow in porous media," Journal of Physical Review E, vol. 54, no. 1, pp. 406-410, 1996.

[48] L. Li and M. Iskander, "Evaluation of dynamic image analysis for characterizing granular soils," Geotechnical Testing Journal, vol. 43, no. 5, 2019.

[49] J. Cai, W. Wei, X. Hu, and D. A. Wood, "Electrical conductivity models in saturated porous media: a review," Earth-Science Reviews, vol. 171, pp. 419-433, 2017.

[50] B. Yu, "Analysis of flow in fractal porous media," Applied Mechanics Reviews, vol. 61, no. 5, p. 050801, 2008.

[51] K. Falconer, Fractal Geometry: Mathematical Foundations and Applications, Wiley, Hoboken, New Jersey, U.S., 2005.

[52] B. Yu and J. Li, "Some fractal characters of porous media," Fractals, vol. 9, no. 3, pp. 365-372, 2011. 